\title{
An effective treatment for penile strangulation
}

\author{
CHAO LI $^{1}$, YUE-MIN XU ${ }^{1}$, RONG CHEN $^{1}$ and CHEN-LIANG DENG ${ }^{2}$ \\ Departments of ${ }^{1}$ Urology and ${ }^{2}$ Orthopedics, The Affiliated Sixth People's Hospital, \\ Shanghai Jiaotong University, Shanghai 200233, P.R. China
}

Received December 6, 2012; Accepted April 18, 2013

DOI: $10.3892 / \mathrm{mmr} .2013 .1456$

\begin{abstract}
The aim of this study was to present our experience of patients with penile strangulation. The clinical data of 6 patients (mean age, 36 years; range, 18-72 years) with penile strangulation caused by a metal hoop are provided, where the duration of strangulation was between $3 \mathrm{~h}$ and 1 month. Among these patients, the case of a 22-year-old patient with a steel hoop entrapment on his penis for 5 days is described; due to serious injury of the skin at the root of penis, an intermediate split-thickness thigh skin graft was used to repair the skin loss. A review of the literature is also provided in this study, and current treatment options and outcomes are evaluated. In all the cases described, the metal hoops were successfully removed, without gangrene of the penis. These patients were discharged 2-27 days later with a satisfactory outcome. Penile strangulation is an unusual clinical condition and the consequences may be severe. The choice of method for removal depends on the type and size of metal hoop, incarceration time, trauma grade and availability of equipment. Early treatment is essential to avoid potential complications, including ischemic necrosis and autoamputation.
\end{abstract}

\section{Introduction}

Entrapment or strangulation of the penis is a rare emergency situation that may lead to a wide range of vascular and mechanical injuries. Urgent treatment is required, as potential delays may lead to irreversible penile ischemia and gangrene. Penile strangulation, though uncommon, may be challenging to manage. As the constricting devices involved are variable, clinicians require the ability to be creative in their attempts to extricate the foreign bodies, and industrial strength devices should be deployed when necessary.

Penile strangulation is an unusual clinical condition that was first reported in 1755 by Gauthier (1). Since then, approximately 120 cases have been reported in the literature worldwide.

Correspondence to: Dr Chao Li, Department of Urology, The Affiliated Sixth People's Hospital, Shanghai Jiaotong University, 600 Yishan Road, Shanghai 200233, P.R. China

E-mail: chaoli1979@126.com

Key words: penile strangulation, treatment
In middle-aged and elderly men, the leading cause of penile injury by foreign bodies is the attempt to increase sexual performance or due to autoerotic intentions (2), while masturbation and sexual curiosity are the leading causes in male adolescents. In infants and children, the foreign body is usually a string (3), thread (4) or hair tied around the penis. The most commonly reported reason for intentionally placing hair around the penis is for enuresis (5-7).

The attachment of foreign bodies to the penis leading to incarceration of the penis has been accomplished using a variety of non-metallic and metallic objects; the only characteristic these objects have in common is circularity (8-16). Entrapment of the penis by an encircling object leads to swelling of the penis distal to the object, due to the initial blockage of venous return and arterial supply. After several hours, penile strangulation may result in ischemic necrosis and gangrene of the tissue. By contrast, the encircling object may block the venous return without any arterial involvement, resulting in massive enlargement of the penis due to lymphedema, which may lead to necrosis as a result of anoxia associated with venous stasis. Additionally, a whole spectrum of various degrees of mechanical penile injuries is recognized, including skin ulceration, urethral injuries, constriction of corpus spongiosum and corpora cavernosa, development of urethral fistula and loss of distal penile sensations. Delayed removal may lead to necrosis, fistula, sepsis and penile amputation (17-19). Gangrene is an uncommon outcome, as each corpus cavernosum has an individual artery, and the thickness of Buck's fascia and corporeal tissue resists pressure on the deep vessels (20).

\section{Materials and methods}

Patients. This study was approved by the Ethics Committee of The Affiliated Sixth People's Hospital, Shanghai Jiaotong University (Shanghai, China) prior to initiation of the study. Written informed consent was obtained from the patients. Between November 2005 and December 2011, 6 cases of patients with penile strangulation caused by a metal hoop (mean age, 36 years; range, 18-72 years) were admitted to our hospital, where the duration of strangulation was between $3 \mathrm{~h}$ and 1 month. All the patients presented to the Emergency Department with a metal hoop (ring or steel hoop) entrapment on the penis, which resulted in significant penile edema, thus preventing its removal. All the patients maintained normal micturition. 


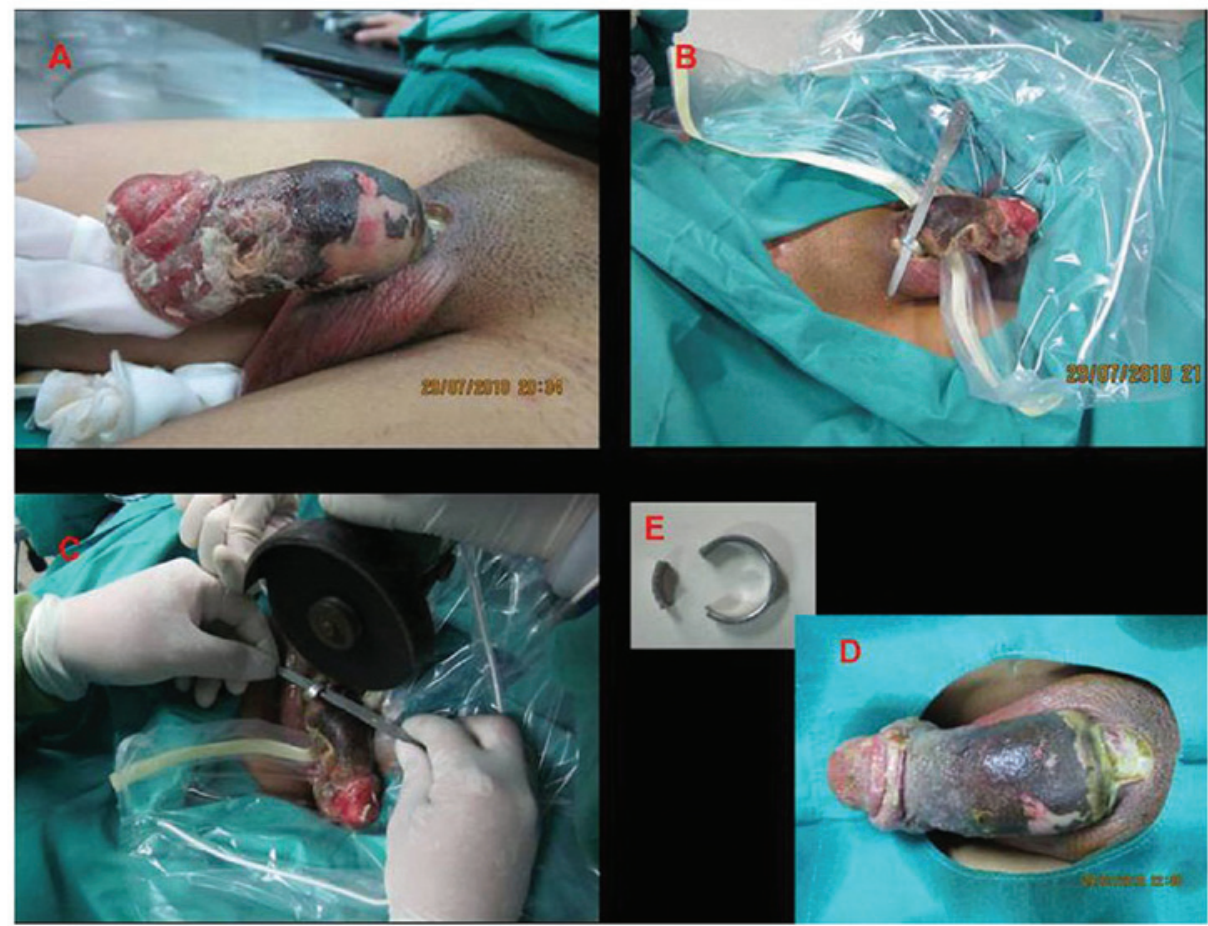

Figure 1. Penile strangulation and removal of steel hoop. (A) Patient with penis strangulation (duration, 5 days) caused by steel hoop on the base of the penis. (B) A metallic strip was placed between the hoop and the penis to protect the skin. (C) The steel hoop was cut with a motor-operated emery wheel machine. (D) Penis following removal and (E) the removed constricting object.

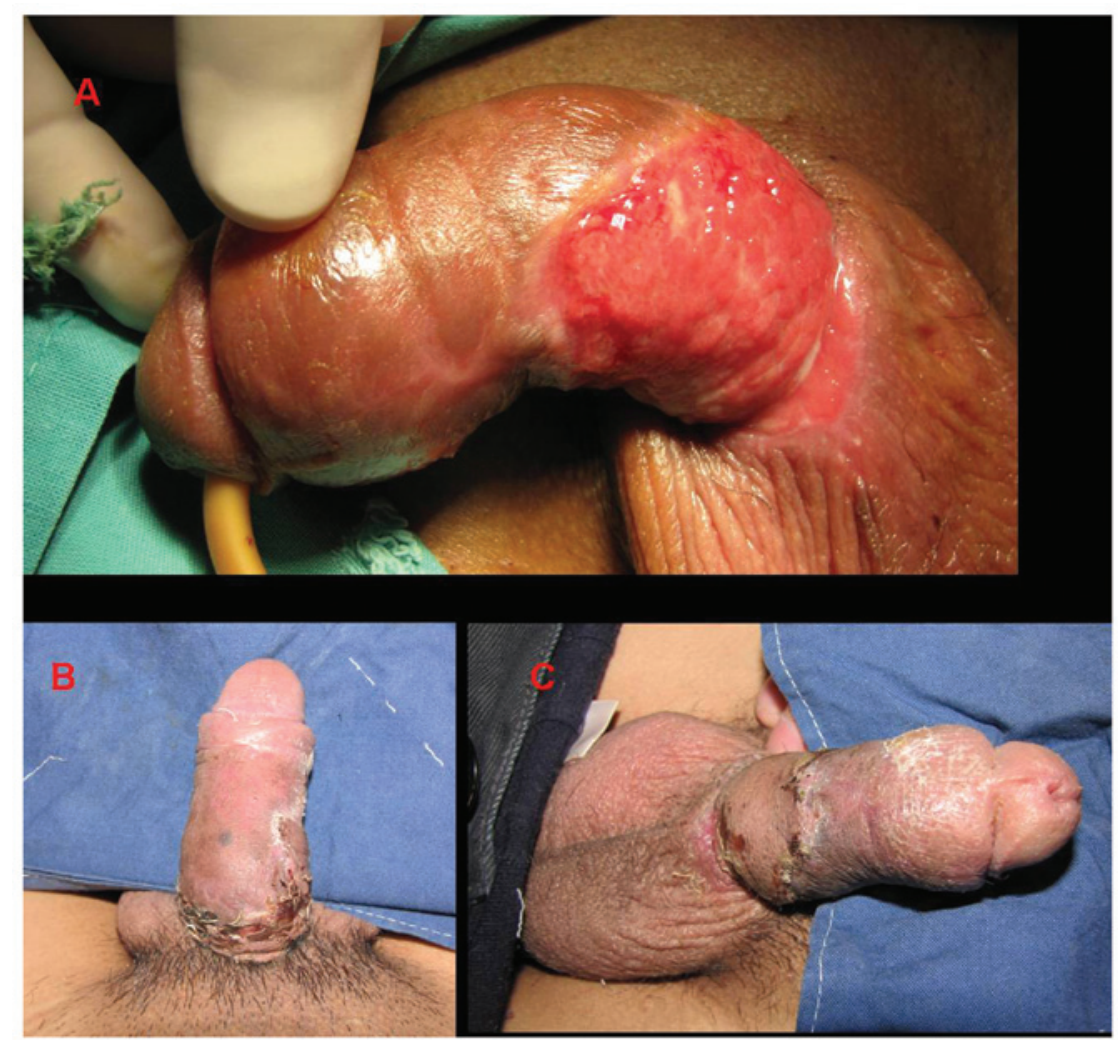

Figure 2. (A) Serious injury of the skin at the root of penis prior to skin grafting; (B and C) The penis following skin grafting.

Among the admitted patients, a 72-year-old patient with penile strangulation (duration, 1 month) presented with evident penile edema; however, cutaneous necrosis had not occurred due to the small diameter of the penis. In addition, a 22-year-old 
patient with penile strangulation (duration, 5 days) presented with a penis that was dark purple in color, with serious cutaneous necrosis and desquamation (Fig. 1A).

Surgery procedure. All the patients were administered a tetanus injection and were subsequently transferred to an emergency operation room; a team of urologists and a technician carried out the removal procedure. Following anesthesia, a metallic strip was placed between the metal hoop and the penis to protect the skin (Fig. 1B). To remove the steel hoop, a motor-operated emery wheel machine was used to create intermittent cuts at two points of the hoop, which was subsequently removed from the penis (Fig. 1C) (Chong Chuan Qu Cheng Bang Power Tools Factory, Nantong, China). Care was required when using the machine, particularly with regard to the following points: i) The patients required a protector to be placed with both ends over the rim of the inner edge of the hoop to prevent damage to the skin and ii) constant rinsing with iced physiological saline was required to prevent the skin from burning.

\section{Results}

The mean operation duration was $36 \mathrm{~min}$. In the case of the 22-year-old patient (penile strangulation duration, 5 days), the removed constricting steel hoop was $16-20 \mathrm{~mm}$ in external diameter (Fig. 1D and E). The metal hoops were successfully removed from all the patients, without gangrene of the penis All the patients were discharged 2-27 days after the original procedure, with a satisfactory outcome. No dysuria or erectile dysfunction was identified during the 3-month follow-up period.

Due to the serious injury of the skin at the root of penis(Fig.2A) of the 22-year-old patient (penile strangulation duration, 5 days), an intermediate split-thickness thigh skin graft was used to repair the skin loss in the Department of Orthopedics of our hospital at day 20 following the procedure. The patient was discharged after 27 days with a satisfactory outcome (Fig. 2B and C).

\section{Discussion}

Chronic penile strangulation by the same mechanism is extremely rare, and only 6 cases have been previously reported (20). This is usually caused by the inappropriate use of devices, developed for autoerotic purposes or to prolong erection, which may be regularly acquired at specialized shops.

Non-metal or thin metal rings are easily removable by severing, but heavy metal rings pose a challenge to emergency physicians and urologists. Various procedures depending on the constricting object have been described for removal (20-23). These include the common metal ring cutter, cutting nippers, metal saw, high-speed drill and string method. Removal is usually performed under anesthesia and the urologist should remove the ring with great care to avoid iatrogenic injury to the external genitalia. Furthermore, removal of these objects may be challenging and require equipment that is not directly available in a urology department. The tools and mechanical methods used are typically selected according to the specific condition (24). In the present study, a motor-operated emery wheel machine was used to cut the steel hoop in two spots; this was provided by the mechanical workers. The metal hoop required a protector to be placed with both ends over the rim of the inner edge of the hoop to prevent damage to the skin.

A grinder, hacksaw, fret-saw or emery wheel machine are tools that are frequently selected to sever a metal object constricting the penis; as a result, significant heat may be produced during the cutting procedure (25). In the present study, to prevent heat damage to the tissue beneath the cutting point, iced physiological saline was applied locally, and rinsing was applied while the preoperative preparations were proceeding. Lower temperatures applied locally protected the tissue by decreasing ischemic-reperfusion injury. The benefit of low temperature locally in the management of penile strangulation requires further evaluation.

When removal of the strangulation object is not possible by any of the aforementioned methods due to the size of the object and/or increased edema, the penis may be denuded, and postoperative treatment follows the principles of severe traumatic penile and scrotal avulsion, including skin grafting $(12,13)$ or the use of a myofascial flap for construction of a neoglans penis (26). Vähäsarja et al (8) described a string method with a glandular incision, which was more simple and rapid compared with previously used methods for removing thick and hardened steel. In the present study, due to the serious injury of the skin at the root of the penis, an intermediate split-thickness thigh skin graft was used to repair the skin loss. No erectile dysfunction was identified during the 3-month follow-up period.

Following the removal of the object, the urethra requires radiological evaluation, particularly in cases where the device has cut through the skin and/or caused ulceration. In such cases, the value of methylene blue in aiding the localization of urethral injury is well recognized (27).

When this is not possible, urinary drainage may be provided by suprapubic tube prior to removal, or urethral catheterization following removal of the strangulation object. Penile block with local anesthetic may improve patient comfort during removal. Patient preparation with parenteral pain medication, tetanus prophylaxis and antibiotics should be considered. Tetanus prophylaxis and pain control has received limited attention in the treatment of penile strangulation in China.

In conclusion, penile incarceration is an urgent matter, with potentially severe clinical consequences. With rapid intervention and removal of the foreign body, a successful outcome may be achieved and no further intervention is required. Early and effective treatment is essential to avoid potential complications, including ischemic necrosis and autoamputation.

\section{Acknowledgements}

This study was supported by the National Natural Science Foundation of China (grant no. 30901503).

\section{References}

1. Gauthier M: Strangulating agents used on the penis, an important cause of gangrene. J Med Chir Pharmacol (Paris) 3: 358, 1755 (In French).

2. Singh B, Kim H and Wax SH: Strangulation of glans penis by hair. Urology 11: 170-172, 1978.

3. Ehrich WS: Two unusual penile injuries. J Urol 21: 239-241, 1929.

4. Harrow B: Strangulation of penis by a hidden thread. JAMA 199: 135,1967 
5. Pantuck AJ, Kraus SL and Barone JG: Hair strangulation injury of the penis. Pediatr Emerg Care 13: 423-424, 1997.

6. Alpert JJ, Filler R and Glaser HH: Strangulation of an appendage by hair wrapping. N Engl J Med 273: 866-867, 1965.

7. Markland C and Merrill D: Accidental penile gangrene. J Urol 108: 494-495, 1972.

8. Vähäsarja VJ, Hellström PA, Serlo W and Kontturi MJ: Treatment of penile incarceration by the string method: 2 case reports. J Urol 149: 372-373, 1993.

9. Hoffman HA and Colby FH: Incarceration of the penis. J Urol 54: 391-399, 1945.

10. Stephens JRW: Penis captivus. Br Med J 1: 662, 1921

11. Sinha BB: Penile incarceration by a metallic object. Br J Surg 75 : 33, 1988.

12. Tiwari VS, Razdan JL and Yadav VN: Strangulation of the penis by a metallic nut. Int Surg 62: 558-560, 1977.

13. Schellhammer P and Donnelly J: A mode of treatment for incarceration of the penis. J Trauma 13: 171-173, 1973.

14. Lopes RI, Lopes SI and Lopes RN: Chronic penile strangulation. Int Braz J Urol 29: 327-329, 2003

15. Mark SD and Gray JM: Iatrogenic penile foreign body. Br J Urol 67: 555-556, 1991.

16. Akkus E, Iscimen A, Tasli L and Hattal H: Paraffinoma and ulcer of the external genitalia after self-injection of vaseline. J Sex Med 3: 170-172, 2006.

17. Stuppler SA, Walker JG, Kandzari SJ and Milam DF: Incarceration of penis by foreign body. Urology 2: 308-309, 1973

18. Tanabe N, Muya M, Isonokami M, Kozuka T, Honda T and Ohtani H: Lymphedema due to chronic penile strangulation: a case report. J Dermatol 23: 648-651, 1996.
19. Sowery RD, Beiko DT and Heaton JP: Long-term penile incarceration by a metal ring resulting in urethral erosion and chronic lymphedema. Can J Urol 11: 2167-2168, 2004.

20. Ivanovski O, Stankov O, Kuzmanoski M, Saidi S, Banev S, Filipovski V, Lekovski L and Popov Z: Penile strangulation: two case reports and review of the literature. J Sex Med 4: 1775-1780, 2007.

21. Dar NR, Siddiqui S, Qayyum R and Ghafoor T: Hair coil strangulation - an uncommon cause of penile edema. Pediatr Dermatol 24: 33-35, 2007.

22. Noh J, Kang TW, Heo T, Kwon DD, Park K and Ryu SB: Penile strangulation treated with the modified string method. Urology 64: 591, 2004.

23. Santucci RA, Deng D and Carney J: Removal of metal penile foreign body with a widely available emergency-medical-servicesprovided air-driven grinder. Urology 63: 1183-1184, 2004.

24. Perabo FG, Steiner G, Albers P and Müller SC: Treatment of penile strangulation caused by constricting devices. Urology 59:137-139, 2002.

25. Xu T, Gu M and Wang H: Emergency management of penile strangulation: a case report and review of the Chinese literature. Emerg Med J 26: 73-74, 2009.

26. Shaeer O and El-Sebaie A: Construction of neoglans penis: a new sculpturing technique from rectus abdominis myofascial flap. J Sex Med 2: 259-265, 2005.

27. Shaeer O: Methylene blue-guided repair of fractured penis. J Sex Med 3: 349-354, 2006. 